premises about ethics consultation from LaPuma and Schiedermayer's: namely that while the 'professionalisation' of ethics consultation may be an inevitability, there is still room to debate the advantages and disadvantages of certification - a point made quite clearly in Susan Sherwin's opening chapter (chapter 1).

There are other differences as well. This text is written by a group of scholars working in Canada, and their observations provide a perspective which, given the similarities between Canada's health care system and others in the west, may make the proposals in this text more accessible internationally. Chapter 7 presents the results of a comprehensive survey of Canadian health care ethics consultants which offers some insight into who is doing what, and how.

The book is not, however, just another collection of individual papers around a central theme. Baylis has arranged the chapters to comment on the novel and illuminating 'profile' of the health care ethics consultant, which she presents in chapter 2 . The objective of the profile is to describe 'knowledge requirements', 'requisite abilities', and 'traits of character' for the health care consultant. The list is comprehensive and instructive, providing a central and powerful heuristic throughout the text by forcing readers, irrespective of their loyalties, to question whether its constitutive components are exhaustive, appropriate and attainable. At the very least, the profile is an important tool for structuring further debate.

Methodologically, this text is far more philosophically grounded than the other; it is not so much a 'practical guide' as an extended discussion, with the profile forming the concrete proposal. In this sense it is inappropriate to compare one with the other since they are not trying to do the same thing.

Lynch's discussion of the skill and abilities which attend to the 'facilitation role' (chapter 3) probes important questions that have not been treated with depth elsewhere in the bioethics literature.

Some topics are treated in both texts, albeit differently. For example, both books discuss the work environment of ethics consultants. In their chapter 'Setting Up Practice' LaPuma and Schiedermayer identify ten issues, and in keeping with the orientation of the book, provide practical guides for what one needs to do. In one of the most enjoyable and stimulating chapters of the Baylis book (chapter 5), Benjamin Freedman provides a tem- plate and a justification for describing the 'median conditions [that] need to be specified on behalf of working conditions, established as of right, on behalf of health care ethics consultants .... More than a list of demands or expectations, it is a philosophical explanation of why it is difficult to produce an adequate job description we have not agreed on the internal morality of health care ethics consultation. But Freedman goes further and offers a reasonable description of the job. Importantly, many of the controversial issues which I suggested that LaPuma and Schiedermayer treated as uncontroversial and resolved, are challenged directly by Freedman (for example, whether consent from a physician is a prerequisite for an ethics consultation).

Legal issues are treated briefly in LaPuma and Schiedermayer as questions about the amount of malpractice coverage one ought to have (pages 79-81), whereas chapter 6 by Lowenstein and Des Brisay in the Baylis book provides a more comprehensive discussion (almost a primer) of the 'facts' relating to liability and the potential for ethics consultants and ethics committees to be found liable for damages as a result of their consultations (which they conclude is unlikely in tort law). Their review of the literature leading to this point is of interest because it is based on some assumptions about the standard of care that any health professional must hold to.

This book is not without some weaknesses. Ironically, one of the weaker chapters is that which is devoted to multidisciplinarity. In chapter 4, 'Feeder Disciplines', individuals from law, medicine, nursing, philosophy and theology provide an assessment of how well or poorly these disciplines meet the standards outlined in the Baylis profile. It is somewhat tedious to read; without the profile handy as a checklist, it is difficult to appreciate how significant are the omissions attributed to each feeder discipline in respect of the profile. It also suffers from falling somewhere between the personal accounts of these highly qualified commentators about how their discipline meets or fails to meet the criteria of the profile, and a general description of this success or failure. There are a few occasions when phrases seem to be repeated in different sections. Sixteen pages are used to provide copies of the survey instrument reported in chapter 7 , and the index is short.

Read alone, this book will suggest to readers that there is much to be gained from having comprehensive knowledge and abilities (and hopefully some of the character traits) of each of several disciplines. This might leave some depressed as they go through the profile comparing themselves to it. A more modest conclusion is that ethics consultation has now come of age as an academic discipline and a professional service. Both books challenge all who profess (or aspire) to 'work in clinical ethics' to come to terms with what this activity entails.

ERIC M MESLIN, PHD Visiting Clinical Ethicist, Oxford Radcliffe Hospital, Visiting Fellow, Green College, Oxford University

\section{Philosophical perspectives on psychiatric diagnostic classification}

Edited by John $Z$ Sadler, Osborne $P$ Wiggins and Michael A Schwartz, Baltimore and London, The Johns Hopkins University Press, 1994, 400 pages, $£ 57.50 \mathrm{hc}, £ 20.50$ sc.

In 1950, the American Psychiatric Association completed its first classificatory manual of psychiatric disorders: Diagnostic and Statistical Manual of Mental Disorders (DSM). The 1980 version (DSM-III), revised again in 1987 as DSM-III-R, is arguably the most influential psychiatric taxonomy in the world today. Among other things, it influences whether psychiatrists will call a person mad, and what kind of madness they will say he or she has.

Contributors to Philosophical Perspectives on Psychiatric Diagnostic Classification were asked to focus on one aspect of DSM, criticise it and offer an alternative. The resulting fourteen essays represent the first detailed analytical examination of the philosophical assumptions and commitments of DSM. The collection also examines the consequences of adopting different nosologies, attempts to clarify the methodological approaches to psychiatric classification and outlines some of the criteria for evaluation of various nosologies. It deals with questions such as: What is a mental disorder? What should be included in the classification of mental 
disorders? How should these disorders be organised?

Edwin E Wallace IV begins by providing a history of classification in psychiatry. Consideration of methodological issues follows. Joeseph Margolis examines DSM's commitment to logical empiricism. $\mathrm{He}$ focuses on Carl Hempel's 'benchmark essay on psychopathological taxonomy', 'Fundamentals of Taxonomy', which is reprinted in the appendix. Schwartz and Wiggins argue for a new hierarchical approach to classification based on the level of knowledge of a particular disorder. Mishara and Kraus illustrate the need for more phenomenological content (the patient's subjective experience of mental illness).

Caws, Mishara, Spitzer and Stephens and Graham evaluate DSM's success in descriptive psychopathology. Spitzer, looking at the hermeneutic nature of the diagnostic process, exposes deficiencies in the definition of hallucinations, delusions and mood congruence. Stephens and Graham approach the issue of voices from the perspective of recent work on the philosophy of mind. They argue that voices are not perceptual disturbances but disturbances of active self-consciousness involving failure of selfascription of speech acts. Caws gives us his own account of subjectivity, interpreting autism, Schizophrenia, Borderline Personality Disorder and dissociative disorders as failures of various aspects of subjectivity.

Bill Fulford, Denise Russell and George Agich expose the covert evaluative commitments of DSM. Fulford artfully demonstrates how value terms are embedded within psychiatric and medical classification. Using Austinian linguistic analysis, he dispels the myth that medical classification and diagnosis can ever be purely descriptive; they necessarily involve value judgments. $\mathrm{He}$ argues that we should give up the sciencebased view of moving from disease concepts (in terms of facts) to concepts of illness (evaluative in terms of patients' experience), to a value-based view in which we move from illness concepts to disease concepts. Agich examines Antisocial Personality Disorder. He is critical of its failure to consider relevant personality traits and context of behaviour. Russell analyses the values inherent in the DSM's account of mental disorder, symptom dysfunction, distress and disability, and a variety of specific disorders. She argues that negative stereotyping of women makes them vulnerable to being diagnosed as suffering from a mental disorder.

The collection closes with prospects for the future. Schaffner examines the issues surrounding a reductionistic model of mental disorder. He reviews two neuroscience models of schizophrenia and examines how far we are on the road to a reductionistic model in terms of neurobiology and molecular genetics. Sadler and Hulgus offer some sensible suggestions to enrich the social and historical context of the individual within DSM-III Axis IV. Goodman presents a case history of his attempts to reorganise psychoactive substance dependence, pathological gambling, bulimia (and compulsive overeating), kleptomania and a number of other behavioural syndromes (including sex addiction) under a single category, 'Addictive Disorders'. It's a lively and passionate piece based on his own observations in clinical practice and past experiences as a bulimic and drug addict.

The contributors come from different backgrounds: they are philosophers of science, general philosophers, and psychiatrists of several persuasions with expertise or interest in philosophy. This makes for an interesting variety of perspectives. Some of the pieces are very good. Some even contain good arguments. But a few are uncontrolled, selfindulgent ramblings remarkable for their fantastic or convoluted assertions. These should not detract too much from the collection as a whole, and perhaps add to its colour.

JULIAN SAVULESCU Department of Philosophy, University of Oxford

\section{Books: information and orders}

If you wish to order or require further information regarding the titles reviewed here, please write to or telephone the BMJ Bookshop, Pळ Box 295, London WC1H 9JR. Tet 0171383 6244. Fax: 017138366620 Books are supplied post free in the UK and for BFPO addresses. Overseas customers should add 15 per cent for postage and packing. Payment can be made by cheque in sterling drawn on a UK bank or by credit card (Mastercard, Visa, or American Express, stating card number, expiry date, and full name (The price and availability are occasionally subject to revision by the publishers) 